\title{
Quiste hidatídico pulmonar bilateral, gigante a derecha y complicado a izquierda
}

\author{
Bilateral pulmonary hydathidic cyst, giant at right and complicated at left
}

Jorge Lavanderos F. ${ }^{1}$ y Marcelo Devaud J. ${ }^{1}$

Paciente de 20 años, de sexo femenino, consulta por tos y dorsalgia. Evaluada con radiografía de tórax se aprecia opacidad redondeada en relación al lóbulo superior derecho (LSD) y condensación más atelectasia del lóbulo inferior izquierdo (LII) (Figura 1). TC de tórax evidencia gran lesión quística multivesicular que sustituye el LSD $(13 \times 8 \mathrm{~cm})$ y lesión quística en LII $(8 \times 6 \mathrm{~cm})$ con aire y membranas colapsadas en su interior (signo del pañuelo) (Figura 2). Se inició antibiótico más albendazol. Se realizó una quistoperiquistectomía parcial por toracotomía bilateral en un tiempo (Figura 3), con buena evolución y alta al séptimo día postoperatorio (Figura 4).

La hidatidosis pulmonar bilateral ocurre entre un 4 a un $26 \%$ de los casos de hidatidosis siendo controversial la técnica y la temporalidad quirúrgica en los casos de bilateralidad ${ }^{1}$. Lo más aceptado es operar primero el lado con el quiste más grande o donde sean más numerosos, por otra parte si hay un quiste no complicado y el otro lado presenta un quiste roto, se comienza por el quiste no complicado. En cuanto a la temporalidad, se describe la toracotomía bilateral simultánea (sincrónica), bilateral separadas por un lapso de tiempo (metacrónica) y en un tiempo por esternotomía o toracotomía de Clamshell, lo más aceptado para la bilateralidad es abordaje por esternotomía en un tiempo o toracotomía bilateral en 2 tiempos $^{2}$, cada abordaje con sus

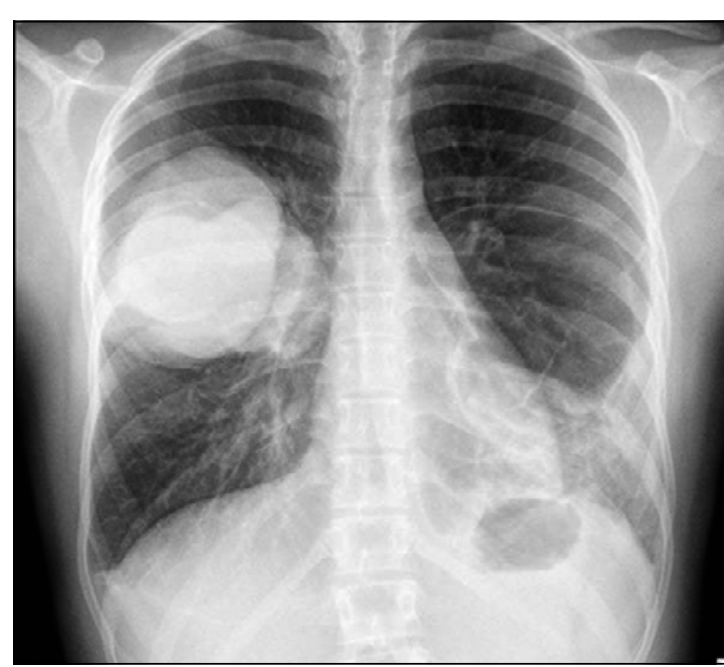

Figura 1. Radiografía de tórax de ingreso.
'Servicio de Cirugía. Hospital Base San José. Osorno, Chile.

Recibido el 1 de mayo de 2019 y aceptado para publicación el 2 de mayo de 2019

\section{Correspondencia a:}

Dr. Jorge Lavanderos Fernández

jlavanderosfernandez@yahoo. com
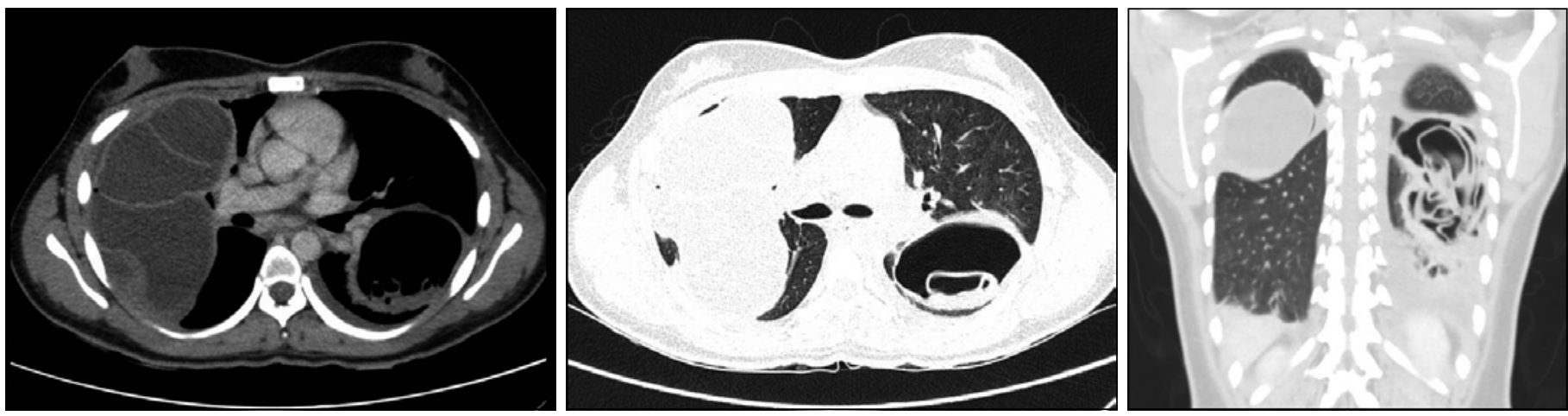

Figura 2. A: Corte axial, ventana mediastino. Quiste gigante a derecha, quiste roto a izquierda. B: Corte axial, ventana pulmonar. A izquierda quiste roto con membranas en el fondo (signo del pañuelo). C: Corte coronal, ventana pulmonar. A derecha quiste que sustituye el LSD, a izquierda signo del pañuelo. 


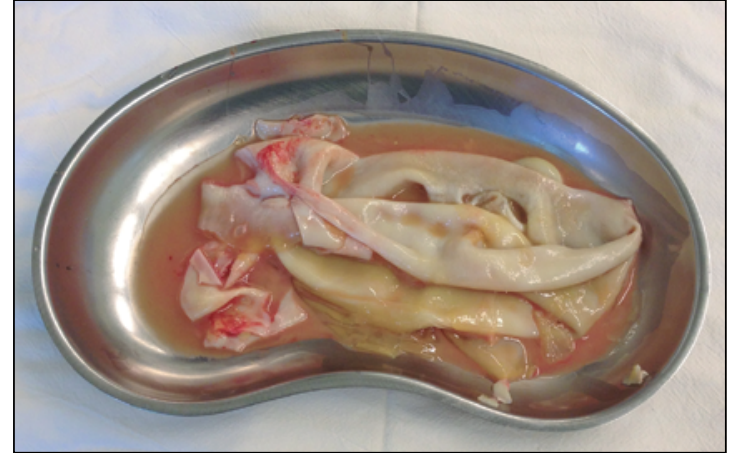

Figura 3. Membranas del quiste gigante (derecho).

ventajas, desventajas y controversias en cuanto a los cuidados perioperatorios ${ }^{1,3}$. La mortalidad aceptada para la cirugía bilateral de la hidatidosis pulmonar va entre 1 a $2 \%{ }^{1}$.

\section{Responsabilidades éticas}

Protección de personas y animales. Los autores declaran que para esta investigación no se han realizado experimentos en seres humanos ni en animales.

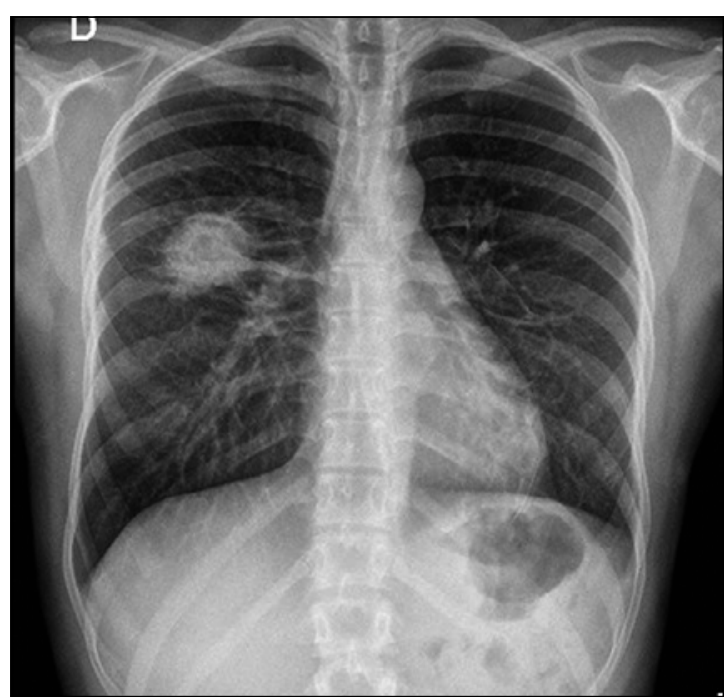

Figura 4. Radiografía de tórax del control post operatorio. A derecha remanente de periquística del LSD.

Confidencialidad de los datos. Los autores declaran que en este artículo no aparecen datos de pacientes.

Conflictos de interés: no hay.

\section{Bibliografía}

1. Hasdiraz L, Onal O, Oguzkaya F. Bilateral staged thoracotomy for multiple lung hydatidosis.
J Cardiothoracic Surg. 2013;8: 121-6.

2. Geraci G, Sciuto A, Lo Nigro C, Sciume C, Li Volsi F, Cupido F, et al. Bilateral lung and liver hydatid cysts. Case report. G Chir. 2012;33: 229-33.

3. Halezeroglu S, Okur E, Tanyü O. Surgical Management for Hydatid Disease. Thorac Surg Clin. 2012;22:375-85. 